\title{
Self-Learning Operation Management for Variable Speed Wind Energy Converters
}

\author{
C. Sourkounis, B. Ni \\ Research Group for Power Systems Technology \\ Faculty of Electrical Engineering and Information Sciences \\ Ruhr-University Bochum, 44801 Germany \\ e-mail: sourkounis@eele.rub.de,ni@eele.rub.de
}

\begin{abstract}
A self-learning power control procedure for variable speed wind energy converters was developed to minimise electric power fluctuation at maximum energy yield. Wind speed is a stochastic changing value, while its probability distribution is subject to seasonal and even daily changes. To take this characteristic into account, a control based on iterative adapting control algorithms was implemented. The new control method was compared to conventional control methods, where it proved to be very effective and yields better results in terms of smooth power output and power coefficient.
\end{abstract}

\section{Key words}

wind energy, adaptive control, optimal control, stochastic optimal control, self-optimisation.

\section{Introduction}

The stochastic fluctuation of wind energy density has a major influence on the operation performance of wind energy converters. Dynamic power flow variations in the power drain of wind energy converters lead, among others things to dynamical torque changes. Especially at locations with turbulent wind characteristics, critical load peaks occur in the power drain. Through the power drain the load peaks are fed forward to the electrical grid and cause premature damage of mechanical components, thermal overloads of electrical components, as well as voltage variations in the electrical grid. Furthermore torque oscillations are induced by load peaks, which additionally stress the components in the power drain.

In principle variable speed wind energy converters (Fig. 1) provide technical possibilities for reducing cumulative load in the power drain and the influence on the electrical grid. The short term wind power fluctuations at the wind rotor can be smoothed by using the rotating masses of the rotor to temporarily store or provide kinetic energy.

Especially designed automatic controls and operation managements are required to temporarily store kinetic energy in rotating masses. The automatic control is a reference variable control, which should set the system to the optimal operating point. The main task of the operation management is to force a power or rotational speed set point for every working condition. Thereby multiple goals have to be tracked:

- Lowest possible fluctuations of the electrical power output

- Low torque changes and load peaks

- As little as possible deviation from the maximum power coefficient of the wind rotor $\mathrm{c}_{\mathrm{P}, \max }$.
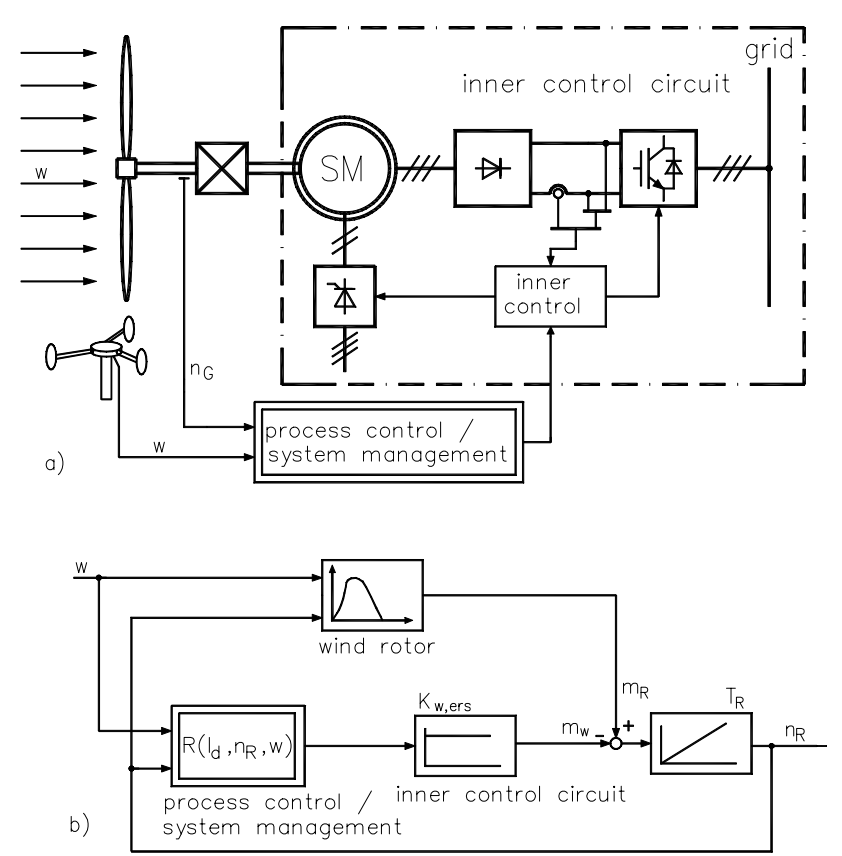

Fig. 1. a) Block diagram of the control concept for a variable speed wind energy converter; b) simplified mathematical model of the process control concept shown in a)

To achieve all goals in a similar manner meets with opposition in case of transient events, because every wind speed change causes a change of the rotational speed set point (or rather a displacement of the optimal 
operating point) and that leads to a control process, which may cause considerable strain on the power drain of the plant and may simultaneously result in additional power fluctuations in the electrical power output.

\section{Control Objectives}

Variable speed operation allows part of the wind rotor energy to be transiently stored in the rotating mass. For every operation state $x\left(n_{R}, w\right)$, it is the system management's task to give a desired value $\mathrm{P}_{\text {ref }}$ for the electrical power output and $I_{d, r e f}$ for the dc-link current. Thereby two objectives have to be pursued:

- The most constant power output of the wind energy converter possible and

- The least possible deviation from the optimal power coefficient $\mathrm{c}_{\mathrm{P}, \mathrm{opt}}$

To quantify at which degree these objectives are fulfilled two indices are introduced:

- Deviation from the average power is characterised by

$$
\mathrm{P}_{-} \text {inde } x=\frac{\sum_{\mathrm{i}=1}^{\infty}\left|\mathrm{P}_{\mathrm{i}}-\overline{\mathrm{P}}\right|}{\overline{\mathrm{P}}} \stackrel{!}{=} \frac{\sum_{\mathrm{i}=1}^{\infty}\left|\mathrm{I}_{\mathrm{d}, \mathrm{i}}-\overline{\mathrm{I}}_{\mathrm{d}}\right|}{\overline{\mathrm{I}}_{\mathrm{d}}},
$$

with the electrical power $\mathrm{P}_{\mathrm{i}}=\mathrm{U}_{\mathrm{i}} \bullet \mathrm{I}_{\mathrm{d}, \mathrm{i}}$, for measurements at time step $i$, and the average electrical power output

$$
\overline{\mathrm{P}}=\frac{1}{\mathrm{~m}} \sum_{\mathrm{i}=1}^{\mathrm{m}} \mathrm{P}_{\mathrm{i}} .
$$

The dc-link current is represented by $I_{d}$, and $U_{d}$ represents the dc-link voltage, which is assumed to be constant.

- Deviation from $c_{\mathrm{P}, \mathrm{opt}}$ is measured by

$$
\mathrm{c}_{\mathrm{P} \_ \text {index }}=\frac{\sum_{\mathrm{i}=1}^{\infty}\left|\mathrm{c}_{\mathrm{P}, \mathrm{i}}-\mathrm{c}_{\mathrm{P}, \mathrm{opt}}\right|}{\mathrm{c}_{\mathrm{P}, \mathrm{opt}}}
$$

with $c_{P, i}=c_{P}\left(\lambda_{i}\right)$, the efficiency of wind rotors, where $\lambda$ is the tip speed ratio.

$$
\lambda=\frac{\mathrm{u}}{\mathrm{w}}=\frac{2 \pi \mathrm{R}_{\mathrm{R}} \mathrm{n}_{\mathrm{R}}}{\mathrm{w}}
$$

The variables are defined as:

$\mathrm{u}$ : tip speed,

$\mathrm{W}$ : wind speed,

$R_{R}$ : radius of wind rotor,

$\mathrm{n}_{\mathrm{R}}$ : rotational speed of wind rotor,

The smaller the indices, the better the objectives are adhered to. Therefore, the weighted sum

$$
\mathrm{q}=\mathrm{g} \cdot \mathrm{P} \_ \text {index }+(1-\mathrm{g}) \cdot \mathrm{c}_{\mathrm{P} \_} \text {index }
$$

has to be minimised, where $0<\mathrm{g}<1$.

An obvious approach is the implementation of a fixed formula for $I_{d, r e f}\left(n_{R}, w\right)$; however, in practice this procedure has some disadvantages. In order to optimally adapt the formula to local wind dynamics, its parameters must be determined from extensive measurements before constructing the installation. Furthermore, firmly set values cannot take into account seasonal and daily differences in wind behaviour.

With consideration of the required computing power, the system management and the algorithm respectively, have to be designed in such a manner, that the complexity of used hardware is kept at a low grade, despite real time conditions. With this aspect, procedures that use an extrapolation of wind speed and then determine $I_{d, i}$ through non-linear optimisation from (5), prove to be too computationally intensive. Therefore the stochastic dynamic programming procedure was adapted to the requirements of wind energy converters. By utilising the principle of optimality, it has very low demand on computational power.

\section{Stochastic Dynamic Optimisation}

A reasonable approach for the given task is stochastic dynamic optimisation with iterative adaptive wind speed probability distribution, given the general name of "iterative self-learning system management" (ISSM). For that purpose the wind energy converter is understood to be a stochastic process.

The goal of the stochastic dynamic optimisation is, in general, to transfer the initial state $\mathrm{x}(0)$ of the addressed system into an final state $\mathrm{x}(\mathrm{K})$ by determining the optimal control trajectory $\mathrm{u}(\mathrm{k})$, under consideration of the minimal cost for the transition process.

The state of the process is described by $x\left(\mathrm{n}_{\mathrm{R}, \mathrm{i}}, \mathrm{w}_{\mathrm{i}}\right)$ The transition from $\left(\mathrm{n}_{\mathrm{R}, \mathrm{i}}, \mathrm{w}_{\mathrm{i}}\right)$ to $\left(\mathrm{n}_{\mathrm{R}, \mathrm{i}+1}, \mathrm{~W}_{\mathrm{i}+1}\right)$ is influenced by the winds stochastic turbulence, the set point value of the dc-link current $I_{d, r e f}$ as a controlling value of the process control, as well as the resulting change in rotational speed of the wind energy converter. The turbulence value $\mathrm{z}$ indicates the wind-speeds relative change:

$$
\mathrm{z}_{\mathrm{i}}=\frac{\mathrm{w}_{\mathrm{i}+1}-\mathrm{w}_{\mathrm{i}}}{\mathrm{w}_{\mathrm{i}}}
$$

The transitional probabilities are a result of the given conditional probabilities $\mathrm{P}(\mathrm{z} \mid \mathrm{w})$ (see chapter 4), in other words, the probability of turbulence $\mathrm{z}$ on the condition that $\mathrm{w}$ is the last measured wind speed.

Figure 2 schematically shows the wind energy converter as a stochastic process with the system management determining the set points. The state values of the process are the wind speed $\mathrm{w}$ and rotational speed $\mathrm{n}_{\mathrm{R}}$, of which only the rotational speed is influenced by the wind energy converter. The wind speed is subject to a stochastic disturbance $z$. The dc-link current $\mathrm{I}_{\mathrm{d} \text {,ref }}$ serves as a controlled variable (reference variable) determined by analysing the control structure. The control structure is not static, but continually updated, noticeably slower than the power set point. Therefore statistical data of the wind speed and dc-link are gathered during operation.

With terms from Operations Research [11], on which this algorithm is based, deviations from the current's average value and from the optimal power coefficient are considered as costs. With that in mind, the cost function $\varphi$ can be defined according to (5), by specifying the influence of the system state $\left(n_{R}, w\right)$, the dc-link current $I_{d}$, and a disturbance $\mathrm{z}$ on the costs: 


$$
\begin{aligned}
& \varphi\left(\mathrm{n}_{\mathrm{R}}, \mathrm{w}, \mathrm{z}\right)= \\
& \mathrm{g} \cdot\left|\frac{\mathrm{I}_{\mathrm{d}}-\overline{\mathrm{I}}_{\mathrm{d}}}{\overline{\mathrm{I}}_{\mathrm{d}}}\right|+(1-\mathrm{g}) \cdot\left|\frac{\mathrm{c}_{\mathrm{P}}\left(2 \pi \mathrm{R} \frac{\mathrm{f}\left(\mathrm{n}_{\mathrm{R}}, \mathrm{w}, \mathrm{I}_{\mathrm{d}}\right)}{\mathrm{w}+\mathrm{w} \cdot \mathrm{z}}\right)-\mathrm{c}_{\mathrm{P}, \mathrm{opt}}}{\mathrm{c}_{\mathrm{P}, \mathrm{ppt}}}\right|
\end{aligned}
$$

Because of the stochastic value $\mathrm{z}$ in (9), it is not possible to explicitly determine the minimal cost; only the expected minimal cost can be calculated. Therefore, the control algorithm has to minimize the expected value of cumulated cost

$$
\underset{z}{E}\left\{\sum_{\kappa=0}^{\mathrm{K}-1} \varphi\left(\mathrm{n}_{\mathrm{R}}(\kappa), w(\kappa), \mathrm{I}_{\mathrm{d}, \mathrm{k}}, \mathrm{z}(\kappa)\right\},\right.
$$

whereby it is generated with all $\mathrm{P}(\mathrm{z} \mid \kappa)$, and $\mathrm{K}$ as the process stop time.

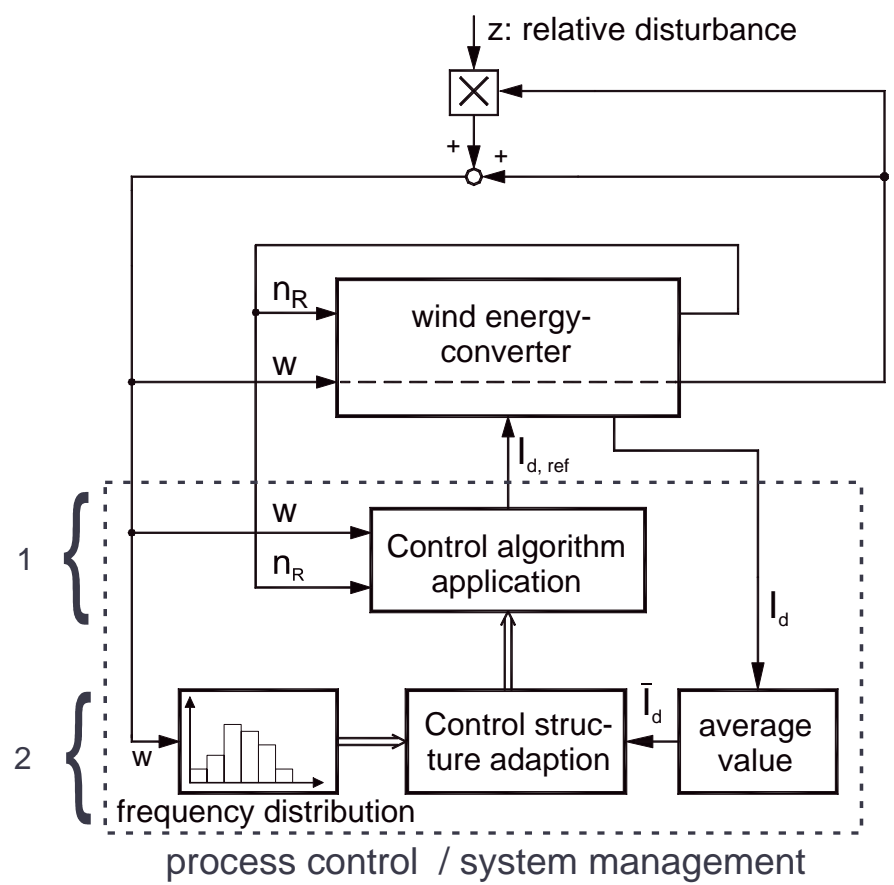

1: execution every calculation cycle

2: e. g. 1 each 100 calculation cycles

Fig. 2. Block diagram of iterative self-learning system management

The minimal expected residual costs are expressed by $\mathrm{V}\left(\mathrm{n}_{\mathrm{R}}(\mathrm{k}), \mathrm{w}(\mathrm{k}), \mathrm{k}\right)$, and by applying the dynamic stochastic optimisation and the principle of optimality to (10), it can be written as [13]:

$$
\begin{aligned}
& \mathrm{V}\left(\left(\mathrm{n}_{\mathrm{R}}(\mathrm{k}), \mathrm{w}(\mathrm{k}), \mathrm{k}\right)=\right.
\end{aligned}
$$

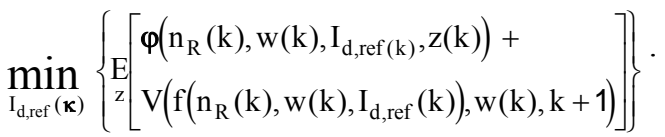

Here the system should not be brought into its final state, but rather should be allowed to run, without a time limit or final condition that must be reached. That is to say that the time horizon is infinite.

In this case, it is possible to determine a time-invariant control structure $\operatorname{Rg}\left(\mathrm{n}_{\mathrm{R}}, \mathrm{w}, \mathrm{k}\right)$ [13], which sets $\mathrm{I}_{\mathrm{d} \text {,ref }}$ to its optimal reference point for each $\mathrm{x}\left(\mathrm{n}_{\mathrm{R}}, \mathrm{w}\right)$. It is necessary for the algorithms convergence that the probability distribution of the wind speed disturbance is timeinvariant. This can be assumed in the above case since convergence, or a constant control structure, is given as long as the probability distribution is constant. If the probability distribution changes then the control procedure will converge to a new value with the new adapted control structure. An iterative adaptive optimisation procedure is, in the sense of the objectives listed above, advantageous for wind energy converters.

Now the minimal cost $\mathrm{V}(\mathrm{x}(\mathrm{k}), \mathrm{k})$ is transformed into $\mathrm{V}(\mathrm{x}(\mathrm{k}))$. The process is set up on the repeated use of saved values $\mathrm{V}\left(\mathrm{n}_{\mathrm{R}}, \mathrm{w}\right)$ independent on $\mathrm{k}$, instead of values $\mathrm{V}\left(\mathrm{n}_{\mathrm{R}}, \mathrm{w}, \mathrm{k}\right)$. That way $\mathrm{V}\left(\mathrm{n}_{\mathrm{R}}, \mathrm{w}\right)$ is iteratively improved for all $\left(\mathrm{n}_{\mathrm{R}}, \mathrm{w}\right)$. This leads, however, to an unlimited increase of $\mathrm{V}\left(\mathrm{n}_{\mathrm{R}}, \mathrm{w}\right)$, since $\mathrm{V}\left(\mathrm{n}_{\mathrm{R}}, \mathrm{w}\right)$ in (11) is always increased by positive values and $\varphi$ does not approach zero. Therefore a weighted sum is introduced in (11):

$$
\begin{aligned}
& \mathrm{V}\left(\left(\mathrm{n}_{\mathrm{R}}(\mathrm{k}), \mathrm{w}(\mathrm{k})\right)=\right. \\
& \left.\min _{\mathrm{I}_{\mathrm{d}, \mathrm{ref}}(\mathrm{k})}\left\{\begin{array}{l}
\mathrm{E} \\
\mathrm{z}
\end{array} \begin{array}{l}
\zeta \varphi\left(\mathrm{n}_{\mathrm{R}}(\mathrm{k}), \mathrm{w}(\mathrm{k}), \mathrm{I}_{\mathrm{d}, \mathrm{ref}(\mathrm{k})}, \mathrm{z}(\mathrm{k})\right)+ \\
(1-\zeta) \cdot \mathrm{V}\left(\mathrm{n}_{\mathrm{R}}(\mathrm{k}-1), \mathrm{w}(\mathrm{k}-1)\right)
\end{array}\right]\right\}
\end{aligned}
$$

with $0<\zeta<1$.

Here, the factor $\zeta$ can be chosen freely. It indicates how strongly the costs of the current condition $\varphi\left(\mathrm{n}_{\mathrm{R}}(\mathrm{k})\right.$, $\left.\mathrm{w}(\mathrm{k}), \mathrm{I}_{\mathrm{d}, \text { ref }}(\mathrm{k}), \mathrm{z}(\mathrm{k})\right)$ take effect in the newly calculated residual costs $\mathrm{V}\left(\mathrm{n}_{\mathrm{R}}(\mathrm{k}), \mathrm{w}(\mathrm{k})\right)$ [10]. The weight-factor therefore influences how quickly the residual costs and therewith the control structure changes. In practice, this means that the pace at which the system management of the wind energy converter adapts to different wind conditions (i.e. a changed frequency distribution) can be set with the value $\zeta$. The value $I_{d, \text { ref }}$, for which the expected value in (12) is minimal, is saved in the control structure $\operatorname{Rg}\left(\mathrm{n}_{\mathrm{R}}, \mathrm{w}\right)$.

Since the up-to-date calculated expected residual costs contain information from the past, the old value of $\mathrm{V}\left(\mathrm{n}_{\mathrm{R}}, \mathrm{w}\right)$ can be overwritten with a newly calculated one. Therefore, the time parameter $\mathrm{k}$ can be eliminated, and the memory demand reduced. $\mathrm{V}\left(\mathrm{n}_{\mathrm{R}}, \mathrm{w}\right)$ is saved as a table for the discrete time and values of $n_{R}$ and $w$, and if need be, linearly interpolated. In order to reduce computational overhead, the search will only be extended to a certain dc-link $I_{d, \text { ref }}$, for which the approximate ascertained rotational speed for that state is contained in the technical limits. In this manner a rotational speed limit is simultaneously realised through the electrical reaction torque.

The algorithm for updating the control structure is programmed as follows:

for all discrete $\mathrm{n}_{\mathrm{R}}, \mathrm{w}$ :

for all discrete $I_{d, \text { ref }}$ calculate $\mathrm{n} \sim_{R}$ if $\mathrm{n}_{\min }<\mathrm{n} \sim_{\mathrm{R}}<\mathrm{n}_{\max }$ : then calculate 


$$
\begin{aligned}
& \mathrm{J}\left(\mathrm{I}_{\mathrm{d}, \text { ref }}\right) \\
& =\underset{\mathrm{z}}{\mathrm{E}}\left[\zeta \varphi\left(\mathrm{n}_{\mathrm{R}}, \mathrm{w}, \mathrm{I}_{\mathrm{d}, \text { ref }}, \mathrm{z}\right)+(1-\zeta) \mathrm{V}\left(\tilde{\mathrm{n}}_{\mathrm{R}}, \mathrm{w}\right)\right] \\
& =\sum_{\mathrm{z}}\left[\zeta \varphi\left(\mathrm{n}_{\mathrm{R}}, \mathrm{w}, \mathrm{I}_{\mathrm{d}, \text { ref }}, \mathrm{z}\right)+(1-\zeta) \mathrm{V}\left(\tilde{\mathrm{n}}_{\mathrm{R}}, \mathrm{w}\right)\right] \cdot \mathrm{P}(\mathrm{z} \mid \mathrm{w}) \\
& \text { select the minimal } \mathrm{J}\left(\mathrm{I}_{\mathrm{d}, \mathrm{ref}}\right) \text { and set } \\
& \mathrm{V}\left(\mathrm{n}_{\mathrm{R}}, \mathrm{w}\right):=\min _{\mathrm{I}_{\mathrm{d}, \text { ref }} \mathrm{J}\left(\mathrm{I}_{\mathrm{d}, \text { ref }}\right):=\mathrm{J}\left(\hat{\mathrm{I}}_{\mathrm{d}, \text { ref }}\right)} \\
& \operatorname{Rg}\left(\mathrm{n}_{\mathrm{R}}, \mathrm{w}\right):=\hat{\mathrm{I}}_{\mathrm{d}, \text { ref }}
\end{aligned}
$$

return.

With this control approach the control trajectory does not reach the state with minimum cost within a certain time period $\mathrm{K}$ anymore, it is rather free to propagate to the next state with less cost than the current state. Provided that the principle of optimality is valid for this control, the system will reach the optimal state with minimal cost.

\section{Self-Learning System Management}

The optimal control structure is applied in the appliances first execution level, where wind speeds $\mathrm{w}$ and rotational speed $n_{R}$ of the wind rotor are measured (Fig. 2). With these measured values, the optimal control value $I_{d, r e f}$ can be determined by utilising the control structure.

Determination and adaptation of the control structure respectively are realised in the second execution level of the ISSM. To adapt the control structure to varying wind conditions, the frequency distribution of $\mathrm{w}$, the mean power output value and the dc-link current are continuously updated. At each calculation cycle of the second execution level, which has a lower execution frequency than the first level, one iteration step is carried out to determine the time invariant control structure $\operatorname{Rg}\left(\mathrm{n}_{\mathrm{R}}, \mathrm{w}\right)$ and the minimal expected residual cost $\mathrm{V}\left(\mathrm{n}_{\mathrm{R}}, \mathrm{w}\right)$.

In order for the operational behaviour of the wind energy converter to be able to be adapted to changing wind conditions, the frequency distribution $\mathrm{P}(\mathrm{z} \mid \mathrm{w})$ needs to be established and updated. If there are only a finite number of values, it can be accomplished by (where "\#" means the number of value of $)$ :

$$
\mathrm{P}(\mathrm{z} \mid \mathrm{w})=\frac{\#\left\{\left(\mathrm{z}^{\prime}, \mathrm{w}^{\prime}\right) \mid \mathrm{w}^{\prime}=\mathrm{w}, \mathrm{z}^{\prime}=\mathrm{z}\right\}}{\#\left\{\left(\mathrm{z}^{\prime}, \mathrm{w}^{\prime}\right) \mid \mathrm{w}^{\prime}=\mathrm{w}\right\}}
$$

Because the equation is divided by the number of measured values and new values are constantly added and the denominator steadily increases. For this reason the influence of newly measured values decreases. Therefore the following frequency distribution is established; If there is a newly measured value $(\mathrm{z}, \mathrm{w})$, with $\mathrm{w}$ being the last measured wind speed and $\mathrm{z}$ being the variation of the current wind speed, then set

$$
\mathrm{P}_{\text {new }}\left(\mathrm{z}^{\prime} \mid \mathrm{w}^{\prime}\right):=\left\{\begin{array}{ll}
(1-\varepsilon) \mathrm{P}_{\text {old }}\left(\mathrm{z}^{\prime} \mid \mathrm{w}^{\prime}\right)+\varepsilon & \text { for }\left(\mathrm{z}^{\prime} \mid \mathrm{w}^{\prime}\right)=(\mathrm{z}, \mathrm{w}) \\
(1-\varepsilon) \mathrm{P}_{\text {old }}\left(\mathrm{z}^{\prime} \mid \mathrm{w}^{\prime}\right) & \text { for }\left(\mathrm{z}^{\prime} \mid \mathrm{w}^{\prime}\right) \neq(\mathrm{z}, \mathrm{w})
\end{array}\right\}
$$

with $0 \leq \varepsilon \leq 1$.

From this, it follows that

$$
\sum_{z^{\prime}} P_{\text {new }}\left(z^{\prime} \mid w^{\prime}\right)=\varepsilon+(1-\varepsilon) \sum_{z^{\prime}} P_{\text {old }}\left(z^{\prime} \mid w^{\prime}\right)=1
$$

with $\mathrm{P}_{\text {new }}$ being the new frequency distribution. On the implementation, the values $\mathrm{P}_{\text {old }}$ will be overwritten by the new values $\mathrm{P}_{\text {new }}$ (s. Fig. 3).
The mean value of the dc-link current is updated similar to the frequency distribution according to

$$
\overline{\mathrm{I}}_{\mathrm{d}, \text { new }}:=(1-\varepsilon) \overline{\mathrm{I}}_{\mathrm{d} \text {,old }}+\varepsilon \mathrm{I}_{\mathrm{d} \text {,mess }}
$$

with $\mathrm{I}_{\mathrm{d} \text {,mess }}$ being the new measured dc-link current.

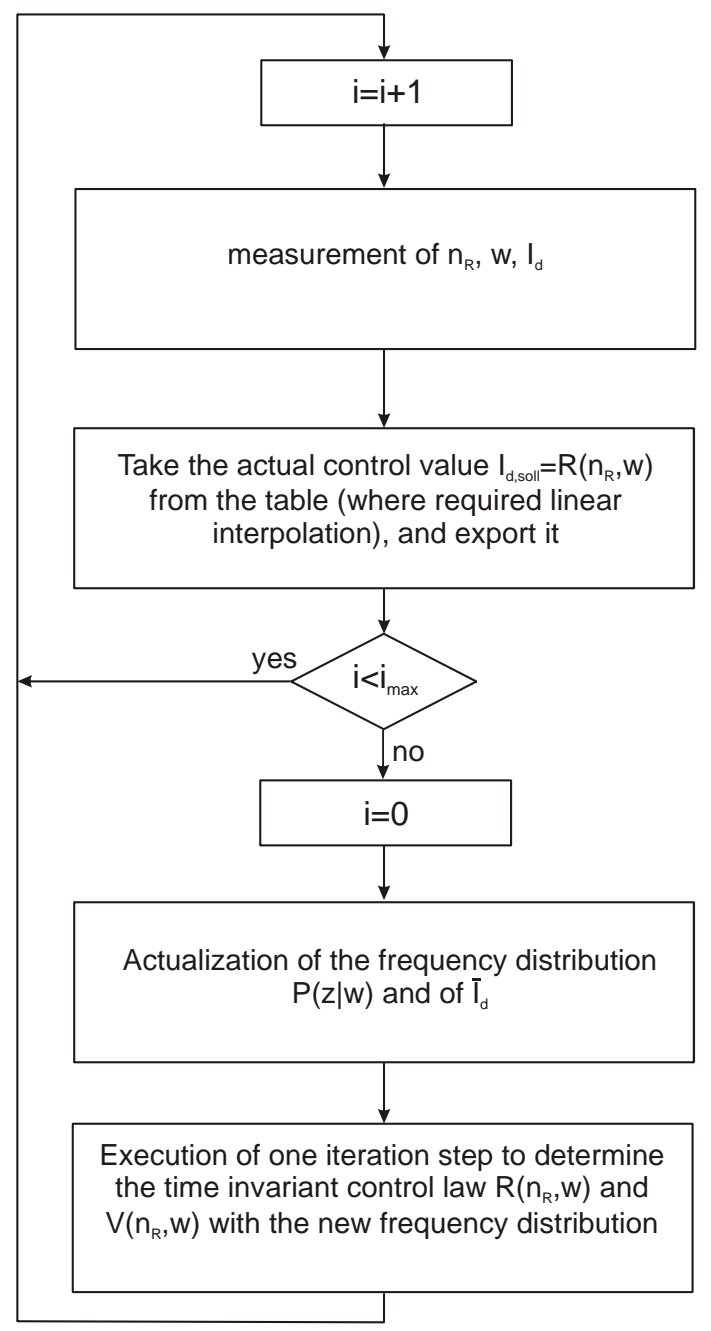

Fig. 3. Scheme of iterative self-adapting control method with varying frequency distribution of the wind speed.

The arbitrary parameter $\varepsilon$ determines the speed at which the values of the wind speed frequency distribution and the mean value of the dc-link current is affected by newly measured values; in other words how fast the change occurs. In principle the parameter $\varepsilon$ can be chosen independently from the discount factor $\zeta$ of the discrete stochastic dynamic optimization. $\zeta$ determines the control structure's adaptation rate. In the following however a consistent parameter $\zeta=\varepsilon$ will be used, so that the rate the wind energy converter adapts to new wind conditions can be adjusted by only one parameter.

\section{Test Results and Comparison to other Control Approaches}

The algorithm was tested by simulations and on a test plant, where a variable speed wind energy converter with a nominal power of $22 \mathrm{kVA}$ was modulated under consideration of the subsystems individual non-linear nature. For this purpose power grid simulation software was used to modulate the individual behaviours of the 
subsystems, rotor, gearbox/shaft, synchronous machine and electric power converter. Some of the technical data of the observed system is given in table 1 .

TABLE I

Technical data of the wind energy converter

\begin{tabular}{|l|l|}
\hline nominal power & $22 \mathrm{kVA}$ \\
\hline nominal speed of generator & $1500 \mathrm{r} . \mathrm{p} . \mathrm{m}$. \\
\hline $\begin{array}{l}\text { total inertia (related to } \\
\text { generator speed) }\end{array}$ & $4.85 \mathrm{Kgm}^{2}$ \\
\hline gear ratio & 23 \\
\hline wind rotor radius & $4.9 \mathrm{~m}$ \\
\hline optimal tip speed ratio & 4.3 \\
\hline dc-link voltage & $440 \mathrm{~V}$ \\
\hline
\end{tabular}

The preset of the current set point with respect to the power set point is carried out by the above given algorithm. The wind speed was read from a file containing the dynamics of different geographical locations (mountains, flat country), created prior with help of pseudo random-number generators. Numerous simulations with differently weighted $\mathrm{P}$ index and

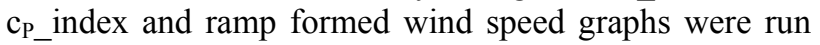
as well (Fig. 8). The stability of the control algorithm for different wind power gradients was thereby tested by varying the frequency of the wind speed characteristic at constant amplitude. The wind power gradient $[\mathrm{W} /(\mathrm{m} 2 \mathrm{~s})]$ is an indication of the wind dynamic, and stands for the area related change of the power contained in the streaming wind mass.
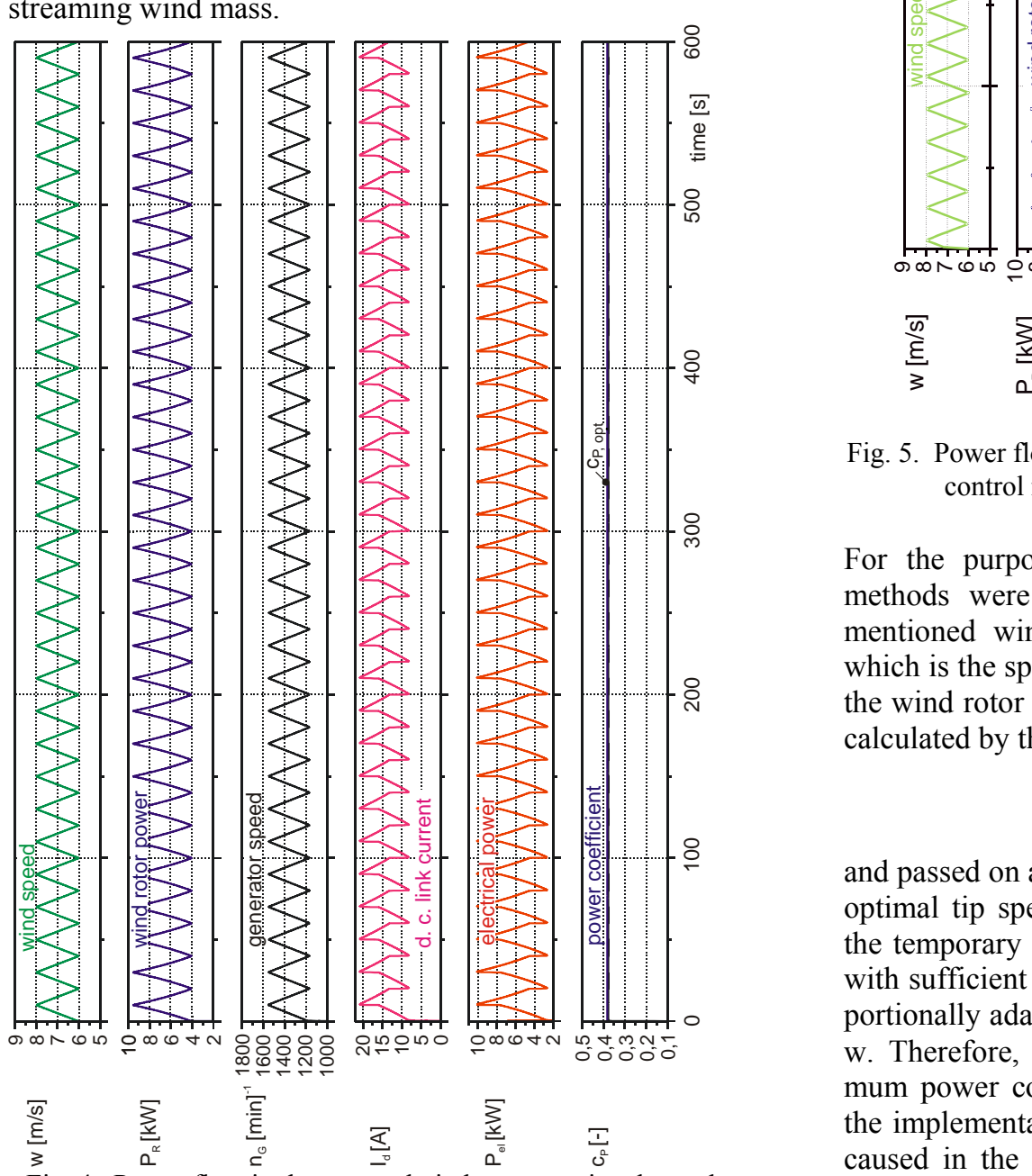

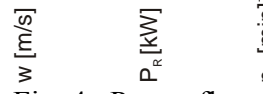

Fig. 4. Power flow in the power drain by conventional speed control method with ramp formed wind speed.
To analyze the investigation results, the wind speed $\mathrm{w}$, rotational speed $n_{R}$, dc-link current $I_{d}$, the electrical power $\mathrm{P}_{\mathrm{el}}$, and the power coefficient $\mathrm{c}_{\mathrm{P}}$ were logged and are shown in Figures 4 to 7 . The resulting calculated $\mathrm{P}$ index provides information about minimizing power variations, and the $\mathrm{c}_{\mathrm{P}_{-}}$index provides information about minimizing deviation from the optimal power coefficient (Fig. 4, 5, 6, 7).

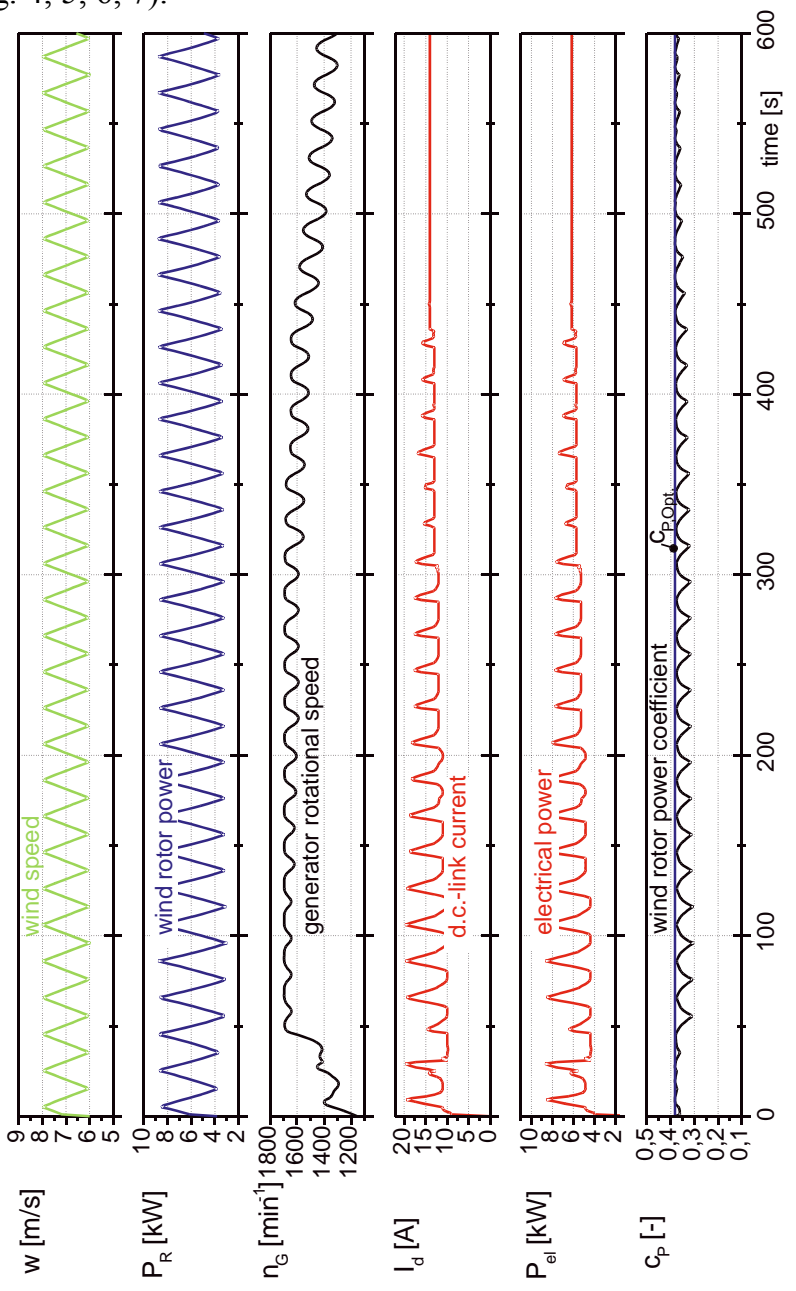

Fig. 5. Power flow in the power drain by iterative self-adapting control method with ramp formed wind speed.

For the purpose of comparison, other power control methods were investigated by the use of the above mentioned wind energy converter model too. One of which is the speed control. The rotational speed, at which the wind rotor converts the maximum possible energy, is calculated by the system management according to

$$
\mathrm{n}_{\mathrm{R}, \mathrm{opt}}=\frac{\lambda_{\text {opt }} \cdot \mathrm{w}(\mathrm{t})}{2 \pi \mathrm{R}_{\mathrm{R}}}
$$

and passed on as the set point. On the assumption that the optimal tip speed ratio $\lambda_{\text {opt }}$ is always constant, and that the temporary value of the wind speed can be measured with sufficient precision, the rotational speed can be proportionally adapted to the currently measured wind speed w. Therefore, the wind rotor always operates at maximum power coefficient $\mathrm{c}_{\mathrm{P} \text {,opt }}$. In practice, depending on the implementation of the speed control, fluctuations are caused in the electrical output, which are subsequently accompanied by disturbances in the grid (e.g. flicker 
effect) and a heavy work load on the drive train (Fig. 4 and 6). Especially transient dynamic fluctuations of wind speed trigger transitional processes. For those short time periods, even a fast adaptation of the rotational speed results in insignificant increases of energy yield only.
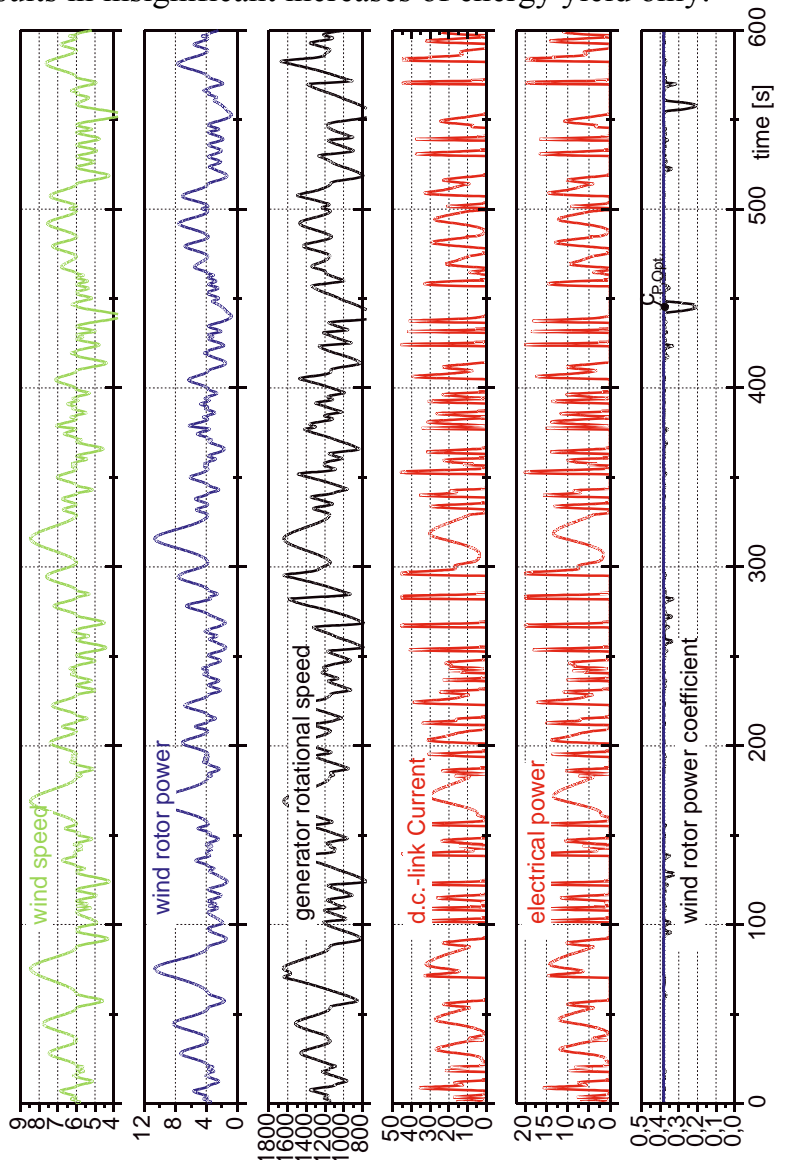

$$
\frac{n}{\xi} \quad \sum_{0}^{\infty} \quad
$$
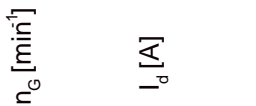

$\underset{0}{\stackrel{5}{ \pm}} \quad \frac{\square}{0^{\circ}}$

Fig. 6. Power flow in the power drain by conventional speed control method with stochastic coastline wind speed

An improvement of the $\mathrm{P}_{-}$index is reached by direct power control methods (Fig. 8 method 2, 3). In comparison to speed control, swings in electrical power output are largely reduced.

At the same time, an additional objective is to reduce the influence of wind gusts, when calculating the reference point. The additionally investigated power control methods differ in the calculation of the power set point. The first one (method 2) averages the wind speed within a fixed time interval. The average is used for calculating the power set point. The second algorithm (method 3) calculates a weighted average from the last measurements of $\mathrm{w}$, according to their probability densities (Weibull distribution).

Figure 8 shows investigation results in comparison. Varied weighting of the $\mathrm{P}$ index $(\mathrm{g})$ and the $\mathrm{c}_{\mathrm{P}}$ index (1g) are assigned during the ISSM-approach with stochastic dynamic optimization and iterative adaptive probability distribution. The greater dynamic of mountainous locations is reflected in the larger index values for all control methods.

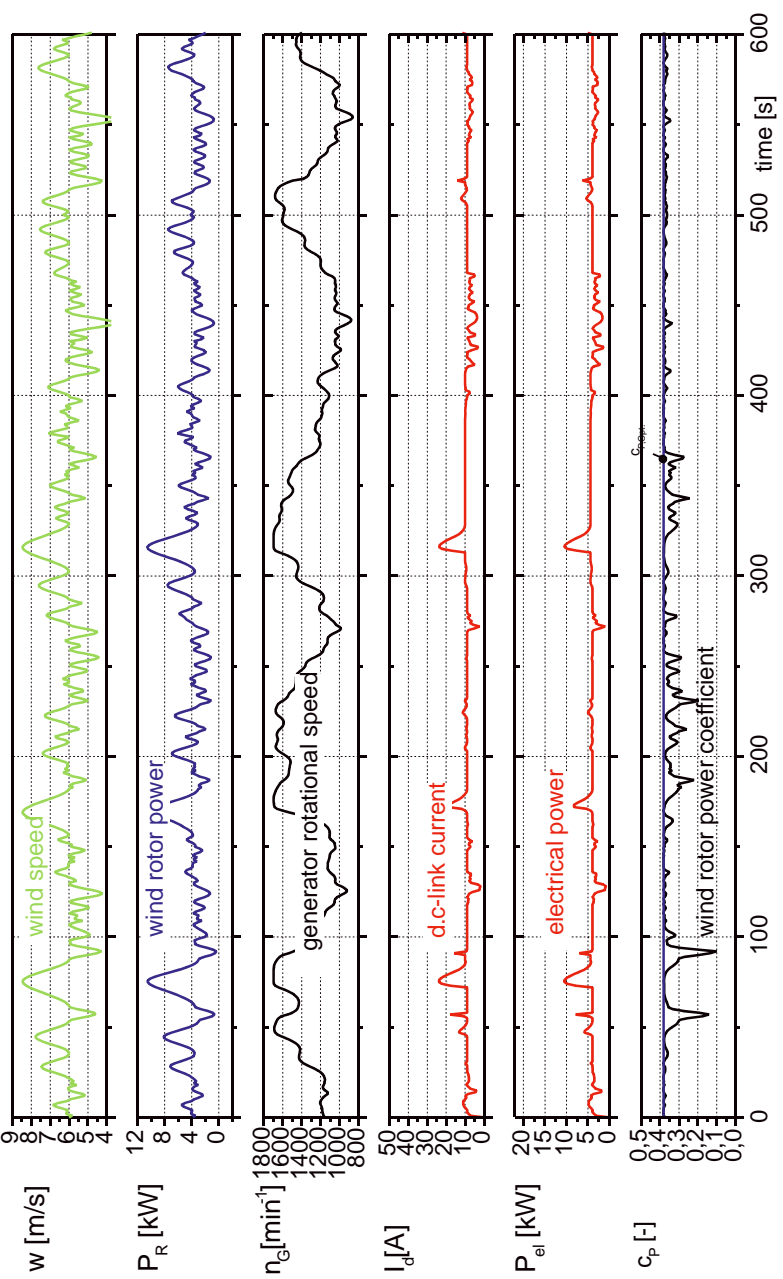

Fig. 7. Power flow in the power drain by iterative self-adapting control method with stochastic coastline wind speed
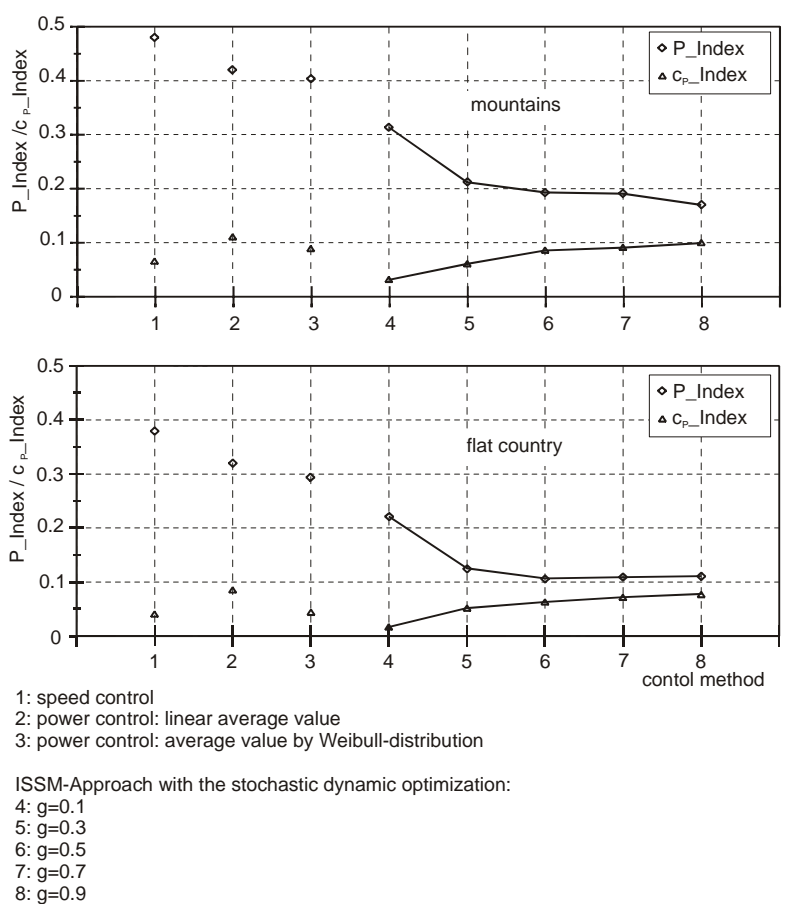

Fig. 8. $\mathrm{P} \_$index and $\mathrm{c}_{\mathrm{P}}$ index by different control methods

When compared to speed control, it is shown that the ISSM-approach offers only a scant improvement in the cp index. This is compensated by a substantial improvement in the fluctuations of electrical power 
output, $\mathrm{P}$ _index, when $\mathrm{g}$ is suitably chosen. As expected, a slightly worse $\mathrm{cP}$ index is the cost of this improvement. Another advantage of the introduced algorithm is that varying wind dynamic at chosen locations are regarded by the iterative adapting wind speed probability distribution, without costly measurements during preliminary stages. This leads to a long term stable power set point and operation of the wind energy converter, which is partially wind controlled and does not trigger control processes due to short-term variations of the wind speed. The storage capacities of the rotating masses are consequently better utilized and a minimum $\mathrm{P}_{-}$index is achieved (see Fig. 5 and 7 also).

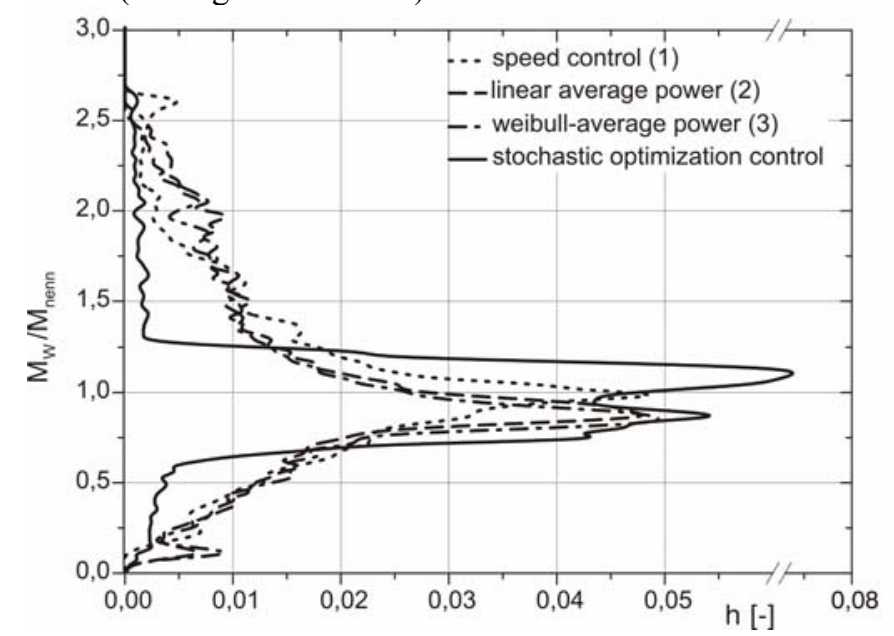

Fig. 9. Histogram of cumulative load of different control methods

Additionally, compared to conventional control methods a clearly visible reduction of the cumulative load in the drive train was also achieved. Figure 9 shows the histogram of the torque value in the mechanical shaft of different control methods. The histogram of torque by ISSM-approach displays explicit a lower load cycle counts with high amplitude. Therefore, by the application of the iterative self-adapting system management, an extended life-cycle of the mechanical components can be expected above all.

\section{Conclusion}

The stochastic dynamic optimisation procedure was adapted to the special needs to serve as a control for variable speed wind energy converter. The demand was to have low demand on computational power, be able to handle processes with infinite time horizon, and be able to adapt to stochastic changing processes. Also three control goals were stated to determine the effectiveness of the control. The goals were lowest possible fluctuation of the electric power output, low torque changes and load peaks, and as little as possible deviation from the maximum power coefficient of the wind rotor $\mathrm{cP}, \max$. Two indices were introduced to determine at which degree the objectives were fulfilled. During test bench runs the adapted stochastic dynamic optimisation procedure proved to be suitable for real time control tasks. Comparison to conventional wind energy converter control approaches showed the advantage of the new approach in terms of low power fluctuation of the energy output while retaining a high power coefficient. In addition the cumulated load in the drive train is also reduced by this new control approach.

\section{References}

[1] C. Sourkounis. Windenergiekonverter mit maximaler Energieausbeute am leistungsschwachen Netz. Dissertation, TU Clausthal, 1994. Clausthal-Zellerfeld: Papierflieger, 1995.

[2] G. Bloch, M.-M. Vollath. Prozessautomatisierung. Teubner, Stuttgart, 1991.

[3] H. Eckhardt. Grundzuege der elektrischen Maschinen. Teubner, Stuttgart, 1982.

[4] O. Foellinger. Regelungstechnik, 8. Auflage. Huething, Heidelberg, 1994.

[5] Topunov, M. V.: A Nonlinear Time-Optimal Control Problem, Automation and Remote Control Journal, Volume 63, Number 7 / July, 2002.

[6] J. Hartung. Statistik, 10. Auflag. Oldenburg, Muenchen, Wien, 1995.

[7] E. Hau. Windkraftanlagen, 2. Auflage. Springer Berlin, Heidelberg, New York, 1996.

[8] S. Heier. Windkraftanlagen im Netzbetrieb, 2. Auflage. Teubner, Stuttgart, 1996.

[9] J.-P. Molly. Windernergie: Theorie - Anwendung Messung, 2. Auflage. Mueller, Karlsruhe, 1990.

[10] C. Sourkounis. Drehzahlelastische Antriebssysteme unter stochastischen Belastungen. Habilitation, TU Clausthal, 2004. Clausthal-Zellerfeld: Papierflieger, 2004.

[11] K. Neumann. Operations-Research Verfahren. Hanser, Muenchen, Wien, 1977.

[12] V. Nollau. Semi-Markovsche Prozesse. Harri Deutsch, Thun, 1981.

[13] M. Papageorgiou. Optimierung, 2. Auflage. Oldenbourg, Muenchen, Wien, 1996.

[14] Clarke, F.: Optimal Control, Stabilization and Nonsmooth Analysis, Springer Berlin / Heidelberg 2004

[15] Christofides, P. D.; El-Farra, N. H.: Control of Nonlinear and Hybrid Process Systems, Springer Berlin / Heidelberg 2005

[16] Jalili, M.; Yazdanpanah, M. J.: Transient Stability Enhancement of Power Systems via Optimal Nonlinear State Feedback Control, Electrical Engineering Journal (Archiv für Elektrotechnik), Volume 89, Number 2 / December, 2006 